\title{
Construction of On-line Oil Monitoring System for Large Machinery Yongliang $\mathrm{Li}^{1, \mathrm{a}}$, Xiaohu Chen ${ }^{1, \mathrm{~b}}$ and Junkang Chen ${ }^{1, \mathrm{c}}$ \\ ${ }^{1}$ Xi'an Institute of High Tech Research, Xi'an710025, China. a1072498492@qq.com, b610740155@qq.com, ${ }^{\mathrm{a}} 2277043533 @ q q . c o m$
}

\begin{abstract}
Through the analysis of the mechanical characteristics of large machinery, complex structure, complex operation conditions and high reliability requirements, once the failure will cause serious economic losses, and even lead to serious casualties of the accident. Fault diagnosis of construction application of on-line oil monitoring system is reasonable in large machinery, can timely carry out fault analysis and condition based maintenance, which ensure the safety of large machinery and reliable operation, avoid economic loss and safety accidents.
\end{abstract}

Keywords: large machinery, malfunction analysis, online oil monitoring system.

\section{Introduction}

With the development of modern science and technology in China, large machinery is widely used in military and civil fields. How to ensure the safe and reliable operation of large machinery ,that is of great significance. Now the prominent characteristics of large machinery are complex structure, powerful, high degree of intelligence. The transmission system of the large machinery is mainly driven by hydraulic pressure, and the working environment of the construction machinery is very easy to be polluted. The survey shows that about $75 \%$ of the fault in the hydraulic system is caused by oil pollution. In fault diagnosis, after more than 30 years of the oil monitoring technology development, now it is a new subject that encompasses a variety of disciplines and cross, and is widely used in many heavy machinery maintenance field, the analysis method and technology are more and more mature and perfect, the effect can be said to be very good. Oil monitoring technology is very important for large machinery intelligent booming, integrated development. In the current information age, communication technology is developed in oil monitoring technology has become a mature fault diagnosis management technology at home and abroad have developed many kinds of oil monitoring sensor, a plurality of sensors and communication the formation of integrated equipment on-line oil monitoring system, fault diagnosis can be applied to large machinery, which can ensure the safe and reliable operation of large machinery. It is of great significance to construct a reasonable on-line oil monitoring system for large machinery fault diagnosis.

\section{Traditional Oil Monitoring Methods}

\subsection{Conventional Rational Analysis}

The conventional rational analysis is the basis of oil monitoring technology, and it is a common method in fault diagnosis of large machinery. Its main contents includes analysis lubricating oil viscosity, density, flash point, mechanical impurities, total acid, water and other indicators. In the specific use of the analysis method, generally do not need to analyze each element, according to the actual situation to select the necessary indicators for testing.

\subsection{Spectrometric Analysis}

The spectral analysis method is mainly through the analysis of composition of pollutants and additives in lubricating oil, to predict oil condition of machines and equipment. This analysis is the core technology of oil monitoring technology currently used in the maintenance of large machinery

\subsection{Ferrography Analysis}

The ferrography analysis method is through a microscope or observed directly wear particle morphology, size and other characteristics, and on the basis of qualitative analysis. The detecting 
speed is fast, large amount of information provided, but for nonmagnetic metal at a loss, so as to cause the measuring result has certain error

\subsection{Oil Contamination Analysis}

This method is mainly adopts the particle counting technique, through filtering and weighing method for particle counting, accurate, fast, convenient, and no limitation of personal experience. It is mainly analysis technique for oil pollution, can reduce the damage of oil pollutants in the machine or system.

\subsection{Regular Offline Monitoring Typically Includes the Following Steps}

(1) Selecting production, product quality and economic benefits of equipment for monitoring objects, in depth understanding of the basis condition of the equipment (function, structure, operation status, lubrication and lubrication system status), to select and formulate reasonable oil monitoring technology scheme.

(2) Selecting the oil sample. Selecting the sample which can represent the wear state of the parts or the state of the lubricating oil, the sample is an important part of the implementation technology.

(3) Oil detection. The detection of oil samples into the monitoring instruments, analyzing related parameters and status of particles and lubricating oil quantitatively, compared with the previous record of the diagnosis found abnormal state of equipment.

(4) Data processing and analysis of detection, according to the different choice of the monitoring technology , can adopt the trend method, analogy method and analysis of data processing results.

(5) According to the results of data processing and analysis, to judge the abnormal, abnormal location, abnormal degree and cause of the equipment, to predict the possible problems and the time, scope and consequence of the abnormal.

(6) Putting forward the improvement measures of the abnormal situation equipment (including the time, content, cost, specific repair plan and implementation).

The traditional oil monitoring mode and implementation of large machinery as shown in Figure 1, The first is the equipment according to oil monitoring plan of headquarters designated, sample registration of large equipment oil. Oil monitoring station is mainly responsible for the monitoring oil indicators, training the person in charge sampling equipment. The measured data is transmitted to the oil monitoring center, analyzing the unusual oil, to determine the fault reasons, formulating specific troubleshooting and maintenance suggestions sent to the main person in charge of each device, allowing them to carry out equipment maintenance and maintenance work.

The fault diagnosis process of large machinery is complex as shown in Figure 1, it is take so much time in the process, which off-line oil detection, data sampling, transmission and analysis, to predict in advance of the occurrence fault and condition based maintenance, especially if a fault occurs to affect the progress of the project, may cause economic losses and major accidents.

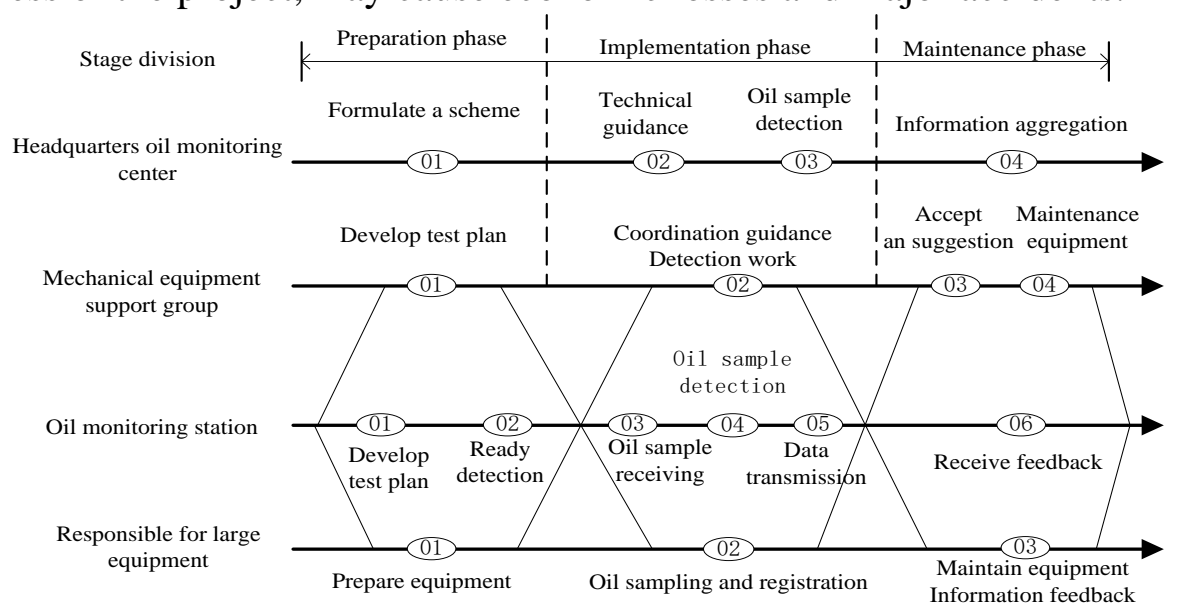

Fig. 1 the implementation of large scale mechanical monitoring in traditional oil monitoring 


\section{Online Oil Monitoring System}

Domestic and foreign technical data statistics, about $80 \%$ of the mechanical parts failure is caused by various forms of wear. The wear of mechanical components will not only destroy the original mechanical relationship caused by vibration and noise, will lead to mechanical strength and function, work reduced precision and reduce production efficiency, so the wear of mechanical parts is the root cause of equipment failure. The lubrication and wear of the equipment are closely related, the lubrication condition of the mechanical friction pair has a direct impact on its wear. It is necessary to monitoring analysis wear state of mechanical equipment under operating condition, found the problems in a timely manner wear equipment, take maintenance measures, to ensure the safe operation of equipment. According to the reason of failure of mechanical fault diagnosis, the main oil parameters affect the mechanical failure are abrasive, viscosity, moisture, the parameters of which is based on physicochemical properties and wear metal particles to obtain equipment lubrication and wear state, judging equipment fault.

Online oil monitoring technology is to use the principle of light electromagnetic physics, which changes oil parameters into analog signal or digital signal, using sensor and computer monitoring and analysis the mechanical oil performance, carrying friction and wear information. It is effective to ensure the safe and stable operation of machinery by analyzing equipment working state and predicting of potential risks and fault. At present, the domestic and foreign research direction mainly concentrates on the single parameter oil detection technology and method. Because of the amount of information contained in mechanical equipment oil , the data is huge and complex, interrelated degree highly, so the single oil detection index or system cannot fully and accurately evaluate the mechanical equipment operation state, modular and multi parameter oil monitoring system is becoming a new research direction, In view of the large mechanical condition is complex and not easy to grasp the fault information, it is easy to appear wear failure and oil inlet, so that the lubrication degree of reduction is not sufficient to protect the normal operation of machinery. The use of integrated on-line monitoring system can real-time grasp the status of large machinery operation. In order to ensure the effectiveness of the monitoring system, it is necessary to select a reasonable monitoring location, select the appropriate sensors and accurate equipment control, the oil online monitoring system design is shown in figure 2.

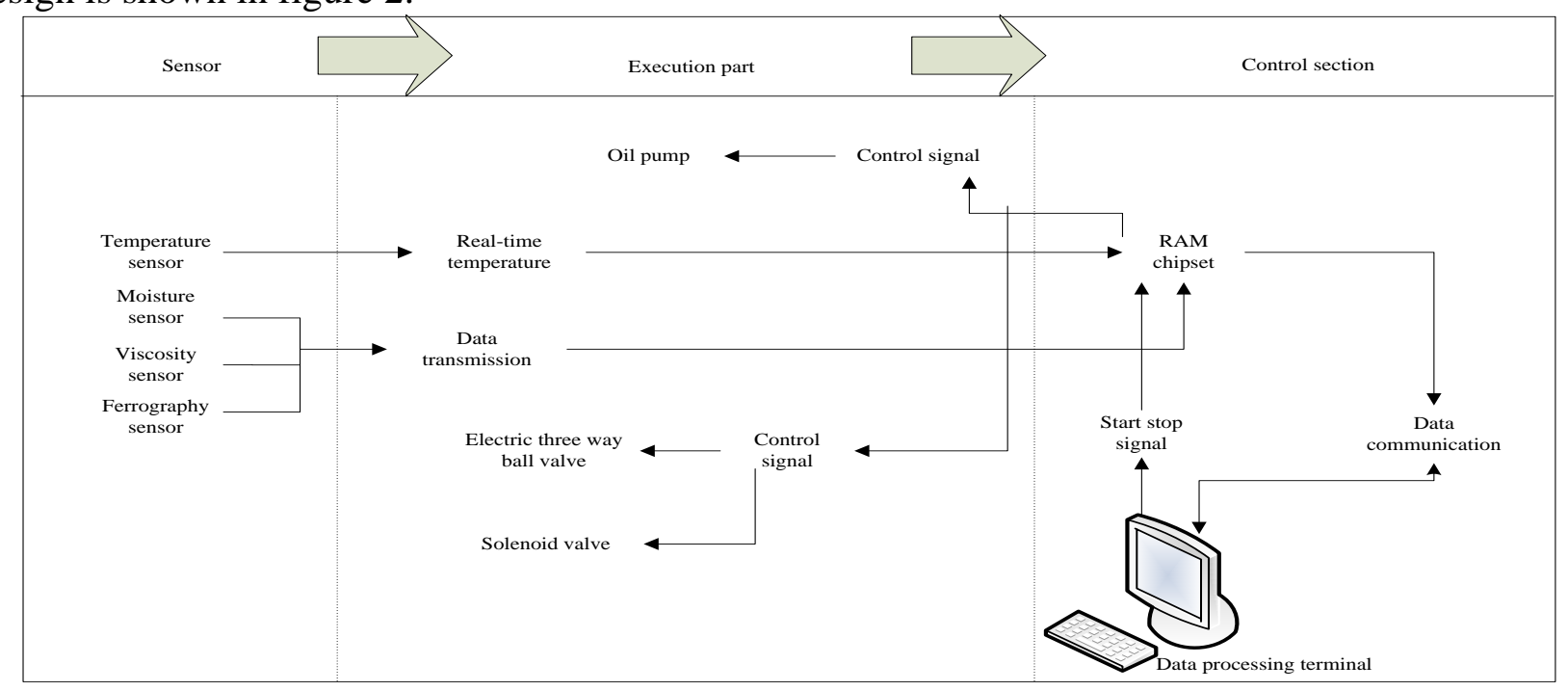

Fig. 2 the oil online monitoring system design

This system is mainly divided into three parts, the first part is the part of the sensor, according to the failure mechanism of large machinery selection of temperature sensor, moisture sensor, viscosity sensor, and ferrography sensor. Sensor is the first link in the detection and control, and plays an important role to accurately detect conditions. The sensor is mainly to accept all kinds of non-electric signals of the tested objects, and converts them into electrical signals: sensors $\rightarrow$ operational amplifier circuits $\rightarrow$ A/D converters $\rightarrow$ computers. However, this signal is generally small, needing to be 
amplified, to improve the signal to noise ratio, suppress zero drift, enhance the ability to resist interference, to meet the requirements of the data acquisition board. The mechanical oil is extracted by the micro oil pump, and then is passed through the temperature, moisture, viscosity and ferrography sensors. The oil must be through a certain order, if the first through the ferrography sensor, the oil part of the abrasive particles magnetized possibly, once again, the viscosity sensor will affect the viscosity data in oil.

The second part is the implementation part that mainly consists of three parts: micro magnetic gear pump oil pump, electric three way ball valve and solenoid valve. The oil pump is mainly used for the oil sampling in machinery working process, and the sampling is mainly in two ways: the first one is the direct sampling at the bottom of the tank, the other is the sampling at oil return pipelines. Table 1 is the characteristics of the two sampling methods, it is based on the accuracy of sampling and the representative of the oil samples. Because the sampling amount of oil is not much, so do not use the oil sump oil drain hole. Electric three way ball valve, solenoid valve is mainly through the control part to control the amount of oil into the pump.

Table 1 Three Scheme comparing

\begin{tabular}{cccc}
\hline $\begin{array}{c}\text { Sampling } \\
\text { methods }\end{array}$ & Method & Advantage & Inferiority \\
\hline $\begin{array}{c}\text { Bottom } \\
\text { oil } \\
\text { extraction }\end{array}$ & $\begin{array}{c}\text { Direct sampling } \\
\text { of oil drain holes } \\
\text { or oil sump }\end{array}$ & $\begin{array}{c}\text { Not affect the oil } \\
\text { return line }\end{array}$ & $\begin{array}{c}\text { Change oil sump drain hole } \\
\text { structure }\end{array}$ \\
$\begin{array}{c}\text { Oil return } \\
\text { line }\end{array}$ & $\begin{array}{c}\text { Three pass } \\
\text { sampling }\end{array}$ & $\begin{array}{c}\text { Relatively simple } \\
\text { operation, easy to } \\
\text { implement }\end{array}$ & $\begin{array}{c}\text { A large number of samples will } \\
\text { have an impact on the oil return } \\
\text { sampling the oil pipeline with the } \\
\text { pump, it may cause the pump to } \\
\text { take time }\end{array}$ \\
\hline
\end{tabular}

The third part is the control part, which is composed of ARM chip group and data processing control terminal, the signal acquisition control part is composed of ADC data acquisition card, gear pump and lower computer ARM chip group. The sensor module is used to collect the data through the communication interface, store and display the data. In the data transmission and management part, the sensor signal collected is transmitted to the host PC through the computer network, and it is stored in the database of the host computer for analysis and use, at the same time, real-time display of the monitoring data of each sensor.

The use of the above system can on-line monitoring in large engineering equipment, At any time, it can monitor the running status of the equipment, the operating condition, the abnormity of the diagnosis equipment, the abnormal position, the abnormal degree and the reason of the equipment when the equipment does not stop or disassemble, so as to predict the possible failure of the equipment, improve the management level of the equipment and improve the maintenance of the equipment, which is an effective way to ensure the normal operation of the equipment and create economic benefits. Online oil monitoring system to monitor large machinery will greatly reduce the investment in human and material resources, remote real-time monitoring of the various indicators of equipment, you can promptly eliminate the hidden trouble, so as to condition based maintenance, predictive maintenance. It can greatly simplify the organization and implementation process of large machinery oil monitoring, the organization and implementation process of large machinery online oil monitoring is shown in Figure 3. In the process of online oil monitoring and implementation in Figure 3 , the system largely reduces the procedure of large machinery oil fault monitoring. 


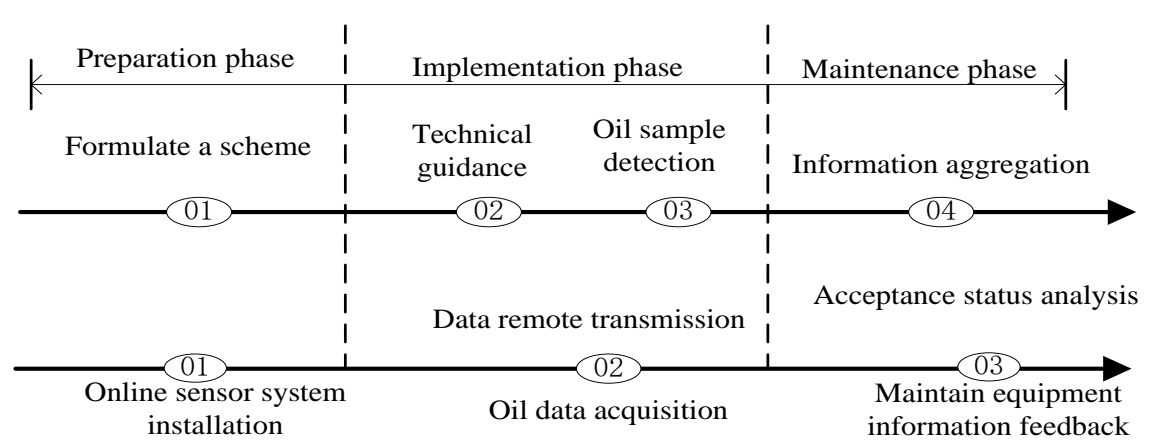

Fig. 3 the implementation of online oil monitoring of large machinery

\section{Conclusions}

At present, the hydraulic pressure system of large-scale construction machinery is developing towards the direction of integration and intelligence, which put forward higher request to the hydraulic oil in the large machinery, it is a very important problem to ensure the stability and reliability of the machine. The online oil monitoring system can be very good for regular tracking and monitoring physical and chemical properties , oil pollution of equipment and wear metal particles, timely understanding of the equipment lubrication and wear state information, diagnosis equipment wear fault type, location and cause. To provide scientific basis for equipment maintenance, guiding enterprises to carry out equipment maintenance and lubrication management, so as to prevent the occurrence of major equipment accident and reduce equipment maintenance costs. So that the reliability of the construction of large machinery can be improved, and the maintenance cost of the equipment under the bad working condition can be saved, at the same time, the service life of the equipment can be prolonged effectively.

\section{References}

[1] Deng Jingwei, Kuang HuaYun, Hydraulic oil pollution analysis and online monitoring technology for large machinery, J. Hydraulic and pneumatic. 2006, pp. 51-59.

[2] Meng XiaoLiang, The application of oil monitoring technology in the equipment management of large maintenance machinery, J. Railway procurement and logistics.2015, pp. 28-29.

[3] Sheng Chenxing, Design of on line oil monitoring sensor for marine diesel engine, Lubrication and seal,J.2012, pp. 102-106.

[4] Wang XiuHui, Implementation of predictive maintenance of equipment based on Oil Monitoring Technology, J. China Equipment Engineering.2011, pp. 19-23.

[5]Shen Yang, Discussion on the function of oil monitoring technology in ship machinery maintenance decision, J. Process and Technology.2011,pp. 45-49.

[6]Wang ZiLu, Development of multi parameter online monitoring system for mechanical equipment, J. Journal of Mechanical Engineering. 2013, pp. 36-40. 